insurance companies who have to set rates; to civil engineers who have to decide how (or whether) to strengthen protections such as levees; and to communities, regions and nations struggling to adapt to long-term changes in climate. If the surge in frequency is a result only of natural cycles, it will probably subside someday soon. But if the increase is a result of global warming, losses and damages could continue rising indefinitely.

Reliable attribution of extreme weather events is also important for the public's understanding of climate change, and to their willingness to support measures to reduce greenhouse-gas emissions. Unlike more distant impacts of global warming such as the slowly rising sea level, the effects of local weather extremes tend to be instantly tangible and vividly remembered. Surveys suggest that people who feel they have personally experienced the effects of climate change are more likely to believe it is a real problem - and one that needs solving - than those who have not.

\section{CHARTING A COURSE}

With those imperatives in mind, the ACE group has set out to explore the climate-weather connection systematically, by feeding observational data from the UK Met Office and the US National Center for Atmospheric Research (NCAR) in Boulder, Colorado, into seasonal forecasts and long-term climate models.

Attribution, however, is no simple task: multiple factors influence a given weather event. Global climate change must have some effect: basic physics suggests that a warmer atmosphere can hold more water vapour, for example, and should therefore develop more storms, which feed on moisture and heat. But natural cycles such as El Niño have an equally obvious effect: freakish weather was a problem for humans long before anyone started pumping industrial quantities of carbon dioxide into the atmosphere.

So the goal of the ACE group is to carry out 'fractional attribution' of extreme events, estimating how much each one was influenced by anthropogenic greenhouse warming and how much by natural cycles (see 'Climate shift'). The studies that appeared in Nature last February ${ }^{1,2}$ offer pioneering examples of how to do this. In one, Pardeep Pall, an atmosphere researcher at the University of Oxford, UK, and his team generated several thousand simulations of the weather in England and Wales during the autumn of 2000. Some of the simulations included observed levels of human-generated greenhouse gases, whereas others did not. The researchers then fed the results of each simulation into a model of precipitation and river run-off to see what kind of flooding would result. In $10 \%$ of the cases, twentieth-century greenhouse gases did not affect the local flood risk. But in two-thirds of the cases, emissions increased the risk of a catastrophic flood - like the one that occurred in 2000 - by more than $90 \%$.

Another group, led by climate scientist Seung-Ki Min of the Climate Research Division of Environment Canada in Toronto, used a similar approach. Inspired by the observation that intense rainfall in the Northern Hemisphere has worsened over the second half of the twentieth century, the group compared actual precipitation data with simulations from six different climate models, both with and without greenhouse warming. They found that the extreme precipitation patterns observed did not match anything expected from natural climate cycles, but closely matched those expected from greenhouse warming.

Such attribution studies can sometimes exonerate climate change. In one published in $\mathrm{March}^{3}$, Randall Dole and his colleagues at the National Oceanic and Atmospheric Administration in Boulder, Colorado, concluded that the intense 2010 Russian heat wave was probably a result of natural cycles.

Although the basic approach seems straightforward, says Stott, fractional attribution is only as good as the climate models that drive it. "We still need to understand which types of weather events we can confidently attribute," he says, "and those for which the models are not yet good enough."

\section{Readmore about} extreme weather attribution: go.nature.com/uard3z

\section{CLIMATE SHIFT}

Extreme weather events - here, very hot or cold temperatures - are rare. But a small rise in the average temperature through greenhouse warming (right-hand curve) can radically increase their frequency. Attribution research tries to quantify this effect for specific events.

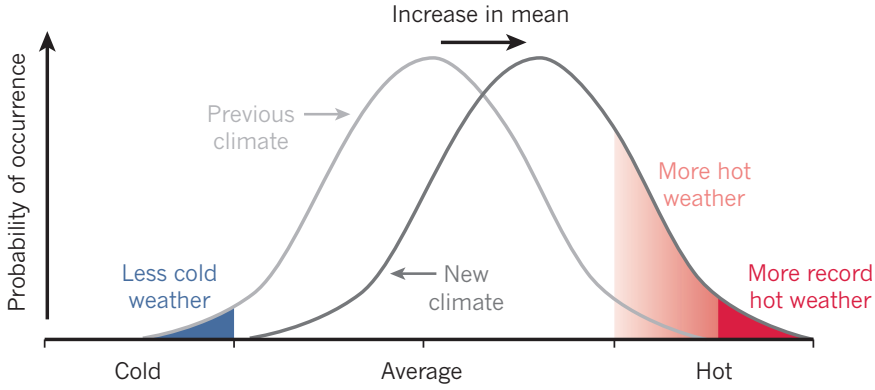

In general, he says, attribution is easiest with heat waves and other temperature-related events. It is much harder with precipitation-related events such as floods and droughts, as the models have to take into account not just rainfall, but soils, natural terrain and human management of rivers and wetlands. And some weather events can't yet be linked to climate change at all. The frequency of tornadoes, for example, depends on a balance between moist air convection, which encourages their formation, and wind shear, which tends to disrupt them - but scientists cannot say for sure how climate change affects that balance.

Another issue is the limited spatial resolution of climate models. At present, for example, they are far too coarse to represent small-scale 'convective' rainfall, a common phenomenon in which warm, moist air near the ground wells up to form an isolated thundercloud. Such convection is especially pronounced — and even harder to model - in mountainous regions such as the Andes or the Himalayas.

Such deficiencies in the models explain why many climate scientists remain sceptical of attribution efforts. "Scientifically unsound" is the assessment of Judith Curry, a climatologist at the Georgia Institute of Technology in Atlanta. Even converts such as Schmidt are cautious. "There is a lot of scope for doing a much better job," he says.

\section{BEYOND THE HORIZON}

The ACE group plans to address these shortcomings in next month's white paper. As a first step, the group suggests that leading centres, such as NCAR and the Met Office, carry out fractional attribution assessments of notable weather extremes over the past 50 years, using large ensembles of coupled climate models and all available weather data. The lessons learned from these retrospective studies could then allow scientists to progress into routine attribution of recent weather, as well as climate-based forecasts of extreme weather.

It is not yet clear what such a plan would cost, or who would pay for it. Kevin Trenberth, a climate scientist with the NCAR, estimates that a few million dollars would be enough to coordinate an international service using facilities already in place at his institution, the Met Office and elsewhere. But going beyond this bare-bones effort - creating, for example, a free-standing attribution centre with monthly, seasonal and decadal forecasting capacities - would cost much more.

Given that governments on both sides of the Atlantic are slashing their budgets wherever possible, Trenberth admits that the prospects for launching such a programme anytime soon seem remote. But neither weather nor climate pays the slightest attention to what policy-makers are doing. And with events such as Hurricane Irene making themselves felt in politicians' backyards, an attribution service might someday be

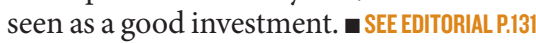

Quirin Schiermeier is a reporter for Nature based in Munich.

1. Pall, P. et al. Nature 470, 382-385 (2011)

2. Min, S.-K., Zhang, X., Zwiers, F. W. \& Hegerl, G. C. Nature 470, 378-381 (2011).

3. Dole, R. et al. Geophys. Res. Lett. 38, L06702 (2011). 